Mathematical Modelling and Analysis

Volume 4, 1999, PAGeS 44-50

(C) 1999 Technika

\title{
THE MATHEMATICAL MODELLING OF THE NONLINEAR HEAT TRANSPORT IN THIN PLATE
}

\section{A. BUIKIS, H. KALIS}

Institute of Mathematics Latvian Academy of Sciences and University of Latvia

Akadēmijas laukums 1, LV-1524 Rīga, Latvia

E-mail: buikis@latnet.lv, kalis@lanet.lv

Received August 28, 1999

\begin{abstract}
The approximations of the nonlinear heat transport problem are based on the finite volume (FM) and averaging (AM) methods $[1,2]$. This procedures allows reduce the nonlinear 2-D problem for partial differential equation (PDE) to a initial-value problem for a system of 2 nonlinear ordinary differential equations(ODE) of first order in the time $t$ or to a initial-value problem for one nonlinear ODE of first order with two nonlinear algebraic equations.
\end{abstract}

\section{MATHEMATICAL MODEL}

We shall consider the nonlinear initial-boundary value problem in the following form:

$$
\begin{gathered}
\partial u / \partial t+v_{0} \partial u / \partial x=\partial(\lambda \partial u / \partial x) / \partial x+F(x, t, u), \\
x \in(0, l), t>0, \\
\lambda \partial u(0, t) / \partial x=f_{1}(t, u(0, t)), \quad t \geq 0 \\
\lambda \partial u(l, t) / \partial x=f_{2}(t, u(l, t)), \quad t \geq 0 \\
u(x, t)=u^{0}(x), \quad x \in[0, l],
\end{gathered}
$$

where $u(x, t), u^{0}(x)$ are the temperature, $v_{0}$ is the transfer velocity $\left(v_{0}=\right.$ const), $l$ is the thin of the plate $(l<<1), \lambda$ is the conductivity $(\lambda=$ const $)$. The function $F$ is the nonlinear heating source arising in chemical reactions, 
for example in the form

$$
F=A H c(u) \exp (-E /(R u)),
$$

where $c, E, H$ are the concentration, activation energy of the burning substance and heat of combustion reaction, $R$ is the universal gas constant $8.31441 \mathrm{~J} /(\mathrm{K}, \mathrm{mol})$, respectively. $A$ is the "pre-exponential" Arhennius factor. The nonlinear functions $f_{1}, f_{2}$ in boundary conditions (1.2), (1.3) describe the radiation from the heaters and the convection, for example

$$
\begin{gathered}
f_{1}=\alpha_{0}\left(u-T_{0}\right)+\epsilon_{0} \sigma\left(u^{4}-\theta_{0}^{4}\right), \\
f_{2}=-\alpha_{1}\left(u-T_{1}\right)-\epsilon_{1} \sigma\left(u^{4}-\theta_{1}^{4}\right),
\end{gathered}
$$

where $\alpha_{0}, \alpha_{1}$ are the convective heat transfer coefficients, $T_{0}, T_{1}$ are the temperature of the environment, $\theta_{0}, \theta_{1}$ denote the temperature of the heaters, $\epsilon_{0}, \epsilon_{1}$ are the coefficients of emissivity, $\sigma$ is the Stefan-Boltzmann constant $5.670310^{-8} W /\left(m^{2} . K^{4}\right)$.

In order to derive the approximate equations we write the PDE (1.1) in the following self-adjoint form

$$
\partial W^{*}(x, t) / \partial x=G^{*}(x, t, u),
$$

where $W^{*}=\lambda e(x) \partial u / \partial x$ is the general flux-function,

$$
\begin{gathered}
G^{*}=e(x) G(x, t, u), \quad e(x)=\exp \left(-v_{0}(x-b) / \lambda\right), \quad b=c o n s t \\
G=\partial u / \partial t-F(x, t, u) .
\end{gathered}
$$

\section{THE FM METHOD}

To derive finite-difference equations associated with the grid points $x=0$, and $x=l$ we integrate the differential equation (1.5) from $x=0$ to $x=l / 2 \quad(b=$ $0)$ and from $x=l / 2$ to $x=l \quad(b=l)$. Therefore we have the integral forms of the conservation law to the intervals $(0, l / 2)$ and $(l / 2, l)$.

The nonlinear 2-point difference equations are in the following form:

$$
\begin{aligned}
& \lambda l^{-1} g(\beta)\left(u_{1}(t)-u_{0}(t)\right)-f_{1}\left(t, u_{0}(t)\right)=R_{0}, \\
& f_{2}\left(t, u_{1}(t)\right)-\lambda l^{-1} g(-\beta)\left(u_{1}(t)-u_{0}(t)\right)=R_{1},
\end{aligned}
$$

where

$$
u_{0}(t)=u(0, t), \quad u_{1}(t)=u(l, t), \quad \beta=v_{0} l / \lambda,
$$




$$
\begin{aligned}
& g(\beta)=\beta /(\exp (\beta)-1)=1-\beta / 2+\beta^{2} / 12-\beta^{4} / 720+O\left(\beta^{6}\right), \\
& R_{j}=\int_{0}^{l} K_{j}(x) G(x, t, u(x, t)) d x, \quad j=0,1, \\
& \left.K_{0}(x)=\exp (\beta(1-x / l))-1\right) /(\exp (\beta)-1) \in[0,1], \\
& K_{1}(x)=(1-\exp (-\beta x / l)) /(1-\exp (-\beta)) \in[0,1] .
\end{aligned}
$$

For the given function $G$ the equations (2.1), (2.2) are the exact approximations for unknown functions $u_{0}(t), u_{1}(t)$. For the approximation of the right side integrals $R_{0}, R_{1}$ we consider the following quadrature formulas:

$$
\begin{aligned}
& R_{0}=l\left(A_{0} G_{0}+A_{1} G_{1}\right)+r_{0}(\eta), \\
& R_{1}=l\left(A_{0}^{*} G_{0}+A_{1}^{*} G_{1}\right)+r_{1}(\eta),
\end{aligned}
$$

where the error terms are given by

$$
\begin{aligned}
& r_{0}(\eta)=0.5 \partial^{2} G /\left.\partial x^{2}\right|_{x=\eta} l^{3} E_{0}, \\
& r_{1}(\eta)=0.5 \partial^{2} G /\left.\partial x^{2}\right|_{x=\eta} l^{3} E_{0}^{*}, \quad \eta \in(0,1), \\
& G_{0}=G\left(0, t, u_{0}(t)\right), G_{1}=G\left(l, t, u_{1}(t)\right), \eta \in(0, l), \\
& A_{0}=g_{3}(\beta), A_{1}=g_{2}(\beta), A_{0}^{*}=g_{2}(-\beta), A_{1}^{*}=g_{3}(-\beta), \\
& E_{0}=g_{4}(\beta), E_{0}^{*}=g_{4}(-\beta), \\
& g_{2}(\beta)=\beta^{-2}(1-(1+\beta / 2) g(\beta)) \\
& \quad=1 / 6-\beta / 24+\beta^{2} / 720+\beta^{3} / 1440+O\left(\beta^{4}\right), \\
& g_{3}(\beta)=\beta^{-1}-\beta^{-2}(1-(1-\beta / 2) g(\beta)) \\
& \quad=1 / 3-\beta / 24-\beta^{2} / 720+\beta^{3} / 1440+O\left(\beta^{4}\right), \\
& g_{4}(\beta)=\beta^{-3}\left(2-\beta-\left(2-\beta^{2} / 6\right) g(\beta)\right) \\
& \quad=-1 / 12+\beta / 60-\beta^{3} / 3360+O\left(\beta^{5}\right) .
\end{aligned}
$$

In the limit case for $v_{0}=0$ we have $\beta=0$. Therefore for the approximate solutions $y_{0}(t), y_{1}(t)$, deleting the error terms $r$ we have from (2.3), (2.4) the following system of nonlinear first order ODE:

$$
\begin{aligned}
\dot{y}_{0}= & F\left(0, t, y_{0}\right)+(l \Delta)^{-1}\left[\lambda l^{-1}\left(y_{1}-y_{0}\right) g_{1}(\beta)\right. \\
& \left.-g_{3}(-\beta) f_{1}\left(t, y_{0}\right)-g_{2}(\beta) f_{2}\left(t, y_{1}\right)\right], \\
\dot{y}_{1}= & F\left(l, t, y_{1}\right)-(l \Delta)^{-1}\left[\lambda l^{-1}\left(y_{1}-y_{0}\right) g_{1}(-\beta)\right. \\
& \left.-g_{3}(\beta) f_{2}\left(t, y_{1}\right)-g_{2}(-\beta) f_{1}\left(t, y_{0}\right)\right],
\end{aligned}
$$

where

$$
\begin{aligned}
g_{1}(\beta) & =g_{3}(\beta) g(\beta)+g_{2}(\beta) g(-\beta) \\
& =\beta^{-1}(1-g(\beta))=1 / 2-\beta / 12+\beta^{3} / 720+O\left(\beta^{5}\right), \\
\Delta & =g_{3}(\beta) g_{3}(-\beta)-g_{2}(\beta) g_{2}(-\beta) \\
& =\beta^{-1}\left(0.5-g_{1}(\beta)\right)=1 / 12-\beta^{2} / 720+\beta^{4} / 30240+O\left(\beta^{6}\right) .
\end{aligned}
$$


The functions $g, g_{1}, g_{2}, g_{3}$ are positive monotone decreasing and they have the following properties:

$$
\begin{aligned}
& g(-\infty)=+\infty, \quad g_{1}(-\infty)=1, \quad g_{2}(-\infty)=g_{3}(-\infty)=0.5, \\
& g_{j}(\infty)=0, \quad j=0,1,2,3, \quad g_{0}=g .
\end{aligned}
$$

The function $g_{4}$ is negative monotone increasing and it satisfies the conditions

$$
g_{4}(-\infty)=-1 / 6, \quad g_{4}(\infty)=0,
$$

and the error terms can be estimated as

$$
\left|r_{j}(\eta)\right| \leq M_{2} l^{3} / 12, \quad j=1,2,
$$

where $\left|\partial^{2} G / \partial x^{2}\right| \leq M_{2}=$ const. The system (2.5), (2.6) must be solved with the initial conditions

$$
y_{0}(0)=u^{0}(0), \quad y_{1}(0)=u^{0}(l) .
$$

\section{THE AM METHOD}

Using the parabolic distribution for the approximation of the function $y$ in the $x$ direction

$$
y(x, t)=\bar{y}(t)+\delta(t)\left(x l^{-1}-1 / 2\right)+\gamma(t)\left(x^{2} l^{-2}-1 / 3\right)
$$

we integrate equation (1.5) from $x=0$ to $x=l, \quad(b=l / 2)$ and divide this expression by $l$ :

$$
l^{-1}\left[\exp (-\beta / 2) f_{2}(t, u(l, t))-\exp (\beta / 2) f_{1}(t, u(0, t))\right]=R_{3},
$$

where

$$
\bar{y}(t)=l^{-1} \int_{0}^{l} y(x, t) d x
$$

is the average value,

$$
R_{3}=l^{-1} \int_{0}^{l} \exp (-\beta(x-l / 2) / l) G(x, t, u(x, t)) d x .
$$

At every time moment $t$ the unknown functions $\delta(t), \gamma(t)$ can be obtained from boundary conditions (1.2), (1.3) and from expression (3.1) in the form of two nonlinear algebraic equations:

$$
\begin{aligned}
& \lambda l^{-1} \delta(t)=f_{1}\left(t, y_{0}(t)\right), \\
& \lambda l^{-1}(\delta(t)+2 \gamma(t))=f_{2}\left(t, y_{1}(t)\right),
\end{aligned}
$$


where

$$
y_{0}(t)=\bar{y}(t)-\delta(t) / 2-\gamma(t) / 3, \quad y_{1}(t)=\bar{y}(t)+\delta(t) / 2+2 \gamma(t) / 3,
$$

or

$$
\gamma=3\left(y_{0}+y_{1}-2 \bar{y}\right), \quad \delta=6 \bar{y}-4 y_{0}-2 y_{1} .
$$

We can represent integral $R_{3}$ in the form

$$
R_{3}=A_{0} l^{-1} \int_{0}^{l} G d x+l B_{0} \partial G /\left.\partial x\right|_{x=\eta}, \quad \eta \in(0, l),
$$

where

$$
A_{0}=2 \beta^{-1} \operatorname{sh}(\beta / 2), \quad B_{0}=A_{0} / \beta-\beta^{-1} \operatorname{ch}(\beta / 2) .
$$

Therefore we have the initial-value problem for nonlinear first order ODE :

$$
\begin{gathered}
\dot{\bar{y}}(t)=F(t, \bar{y}(t))+l^{-1}\left(g(\beta) f_{2}\left(t, y_{1}(t)\right)-g(-\beta) f_{1}\left(t, y_{0}(t)\right)\right. \\
\bar{y}(0)=l^{-1} \int_{0}^{l} u^{0}(x) d x .
\end{gathered}
$$

This problem must be solved together with algebraic equations (3.3). The simplest form of the AM-method yields nonlinear ODE (3.4) with $y_{1}=y_{0}=\bar{y}$ $(\delta=\gamma=0)$.

\section{NUMERICAL RESULTS}

We consider the process of glass fabric manufacturing (with thickness $l=$ $0.1 \mathrm{~mm}$ ) at the glass fiber plant in the Valmiera city (Latvia). An oil must be removed by heating and burning process[1,3]. The initial-boundary value problem for nondimensional system of $\operatorname{PDE}\left(x=\tilde{x} l, c=\tilde{c} c_{0}, u=\tilde{u} \theta_{0}, v_{0}=\right.$ $0, T_{0}=T_{1}, \alpha_{0}=\alpha_{1}, \epsilon_{0}=\epsilon_{1}$, the "wave" symbol is deleted) is in the following form:

$$
\begin{aligned}
& \partial u / \partial t=a_{1} \partial^{2} u / \partial x^{2}+a_{7} c \operatorname{ex}(u), \\
& \partial c / \partial t=-a_{8} c \operatorname{ex}(u), \\
& f_{1}(t, u(0, t))=a_{2}\left(u^{4}(0, t)-1\right)+0.5 a_{3}\left(u(0, t)-a_{4}\right), \\
& f_{2}(t, u(1, t))=a_{2}\left(a_{5}-u^{4}(1, t)\right)+0.5 a_{3}\left(a_{4}-u(1, t)\right), \\
& u(x, 0)=a_{6}, \quad c(x, 0)=1,
\end{aligned}
$$

where

$$
\begin{aligned}
& \operatorname{ex}(u)=\exp \left(a_{9}\left(1-u^{-1}\right)\right), a_{1}=\lambda l^{-2}=160.415, a_{2}=\sigma \epsilon_{0} \theta_{0}^{3} / l=1.72, \\
& a_{3}=2 \alpha_{0} / l=0.06, a_{4}=T_{0} / \theta_{0}=0.8842, a_{5}=\left(\theta_{1} / \theta_{0}\right)^{4}=0.5635, \\
& a_{6}=u^{0} / \theta_{0}=0.2698, a_{7}=c_{0} H A \exp \left(-E /\left(R \theta_{0}\right)\right) / \theta_{0}=51.26 \\
& a_{8}=A \exp \left(-E /\left(R \theta_{0}\right)\right)=128.68, a_{9}=E /\left(R \theta_{0}\right)=17.14
\end{aligned}
$$


$c_{0}$ is the initial concentration of oil. The ODE for the concentration of oil has the form

$$
\dot{c}(t)=-a_{8} c(t) e x(u),
$$

where $c=c(0, t)=c_{0}(t)$ and $c=c(1, t)=c_{1}(t)$ for the FM method, $c=\bar{c}(t)$ for the AM method.

The numerical solutions of the stiff problems of ODE (2.5), (2.6), (3.4), (4.2) are obtained with the routines "gear", "mgear", "lsode" of "MAPLE". Figure 1 shows typical results of calculations: the fabric temperature rises to the maximum value and the oil concentration is falling to zero over a "burning zone" in the time interval [0.26, 0.31].

In the table 1 we can see the numerical values of temperature $y_{0}(t), y_{1}(t)$ in this zone, obtained by the FM and AM.

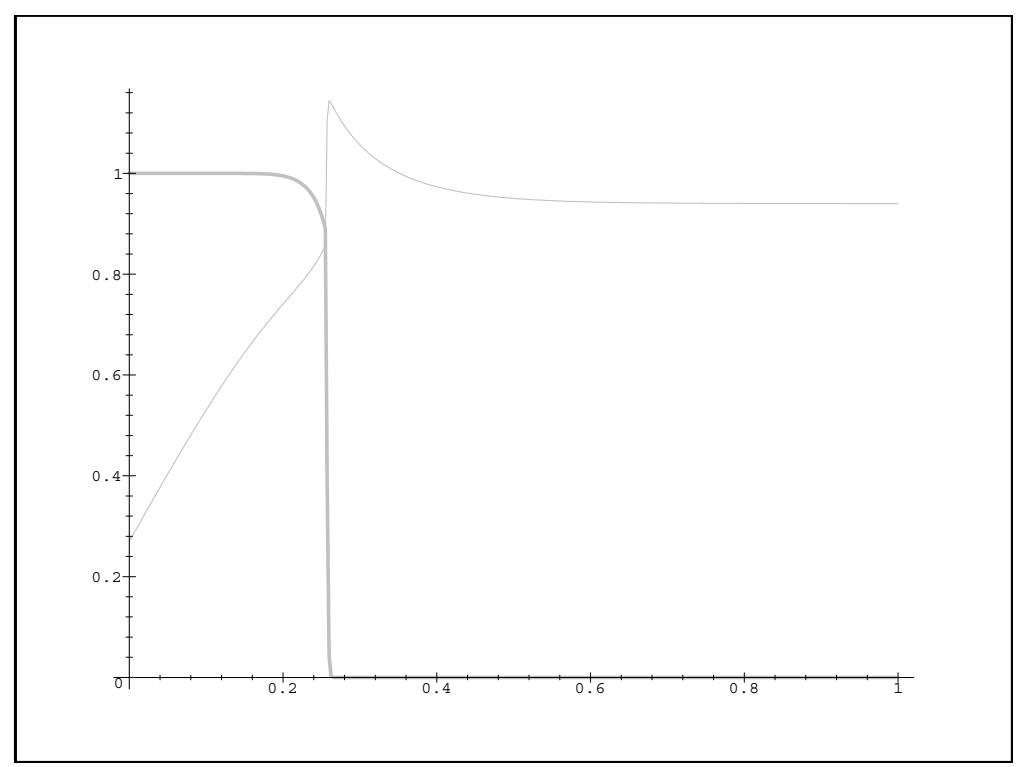

Figure 1. The graphics of the temperature $\bar{y}$ and the concentration $c$.

The values of the concentration $c$ are the following

Table 1 .

The values of temperatures for the FM and AM.

\begin{tabular}{ccccc}
\hline$t$ & $y_{0}(A M)$ & $y_{1}(A M)$ & $y_{0}(F M)$ & $y_{1}(F M)$ \\
\hline 0.26 & 0.8754 & 0.8731 & 0.8769 & 0.8745 \\
0.27 & 0.9470 & 0.9448 & 0.9526 & 0.9501 \\
0.28 & 1.1929 & 1.1907 & 1.1932 & 1.1910 \\
0.29 & 1.1551 & 1.1530 & 1.1550 & 1.1527 \\
0.30 & 1.1244 & 1.1221 & 1.1240 & 1.1218 \\
0.31 & 1.0991 & 1.0970 & 1.0986 & 1.0963 \\
\hline
\end{tabular}


1) $c_{0}(0.26)=0.8457, c_{1}(0.26)=0.8538, \bar{c}(0.26)=0.8532$,

2) $c_{0}(0.27)=0.6616, c_{1}(0.27)=0.6761, \bar{c}(0.27)=0.6824$,

3) $c \leq 10^{-4}, \quad t \geq 0.28$.

For testing the methods we consider only heating process $\left(A=a_{8}=a_{7}=\right.$ $0)$. Then the temperature distribution $u(x, t)$ can be obtained from (4.1) by using the Laplace transform for value $t$ in the form of a sequence of functions $u_{m}(1, t), m=1,2,3, \ldots$, which are the solutions to nonlinear the system of Volterra integral equations of the second kind.

The results of the comparison are given in the table $2\left(u_{0}, u_{1}\right.$ are the exact values by $m=6$ ).

\title{
REFERENCES
}

[1] A. Buikis and A.D. Fitt. A mathematical model for the heat treatment of glass fabric sheets. IMA Journal of mathematics applied in business and industry, 9, 1998, 1-32.

[2] H.Kalis . Finite-difference scheme for solving of some heat transfer problems with convection in multilayer media. In: Proc. of the 2-nd Intern. Conference, Minsk, Belarus, 1998, Finite- difference methods: theory and applications, 2, 1998, 50-55.

[3] A.Buikis, H.Kalis and R.Millere. A model of intensive oil burn out from glass fabric. Mathematical Modelling and Analysis, 5, 1999, 18-25.

\section{NETIESINIO ŠILUMOS PERNEŠIMO PLONOSE PLOKSTELESE MATEMATINIS MODELIAVIMAS}

\author{
A. BUIKIS, H. KALIS
}

Darbe sprendžiamas netiesinis šilumos pernešimo uždavinys. Uždavinio specifika yra ta, kad šilumos pernešimas vyksta labai plonose plokštelèse, todèl nagrinëjamas vienmatis apibendrintas modelis. S̆i redukcija atliekama baigtinių tūrių ir vidurkinimo metodais. Gautoji dviejų netiesinių paprastųjų diferencialinių lygčių sistema yra sprendžiama skaitiškai. Išnagrinètas ir alternatyvus varijantas, kai po redukcijos gaunama viena netiesinè paprastoji diferencialinè lygtis bei dvi papildomos algebrinès lygtys.

Table 2.

Comparison of the numerical results.

\begin{tabular}{ccccccc}
\hline$t$ & $y_{0}(A M)$ & $y_{1}(A M)$ & $y_{0}(F M)$ & $y_{1}(F M)$ & $u_{0}$ & $u_{1}$ \\
\hline 0.1 & .5330 & .5299 & .5318 & .5295 & .53262 & .53044 \\
0.2 & .7412 & .7388 & .7408 & .7385 & .74106 & .73889 \\
0.3 & .8621 & .8603 & .8622 & .8599 & .86202 & .85987 \\
0.4 & .9139 & .9123 & .9139 & .9116 & .91365 & .91150 \\
0.5 & .9321 & .9309 & .9322 & .9299 & .93208 & .92993 \\
\hline
\end{tabular}

